\title{
PENERAPAN PROGRAM PENCEGAHAN COVID-19 PADA ANAK BERBASIS DARING DI DESA MARGAJAYA RT/RW 03/05 KECAMATAN BOGOR BARAT
}

\author{
Rizaldy Jasmin¹, Andi Asnifatima² \\ 1.2Program Studi Ilmu Kesehatan, Fakultas Ilmu Kesehatan Universitas Ibn Khaldun Bogor \\ Email :1jasmin.rizaldy@gmail.com, ${ }^{2}$ asni@uika-bogor.ac.id
}

\begin{abstract}
Abstrak
Kelurahan Margajaya merupakan salah satu daerah yang terletak di Kecamatan Kota Bogor Barat Kota Bogor Provinsi Jawa Barat, Indonesia. Masyarakat di daerah tersebut, sebagian besar mendirikan usaha warung/toko disekitar tempat tinggalnya dan hampir seluruh masyarakat kelurahan masyarakatnya menganut agama islam. Pada tanggal 17 Agustus 2020 sampai tanggal 17 September 2020 Alhamdulillah kami telah melaksanakan program pengabdian masyarakat, selama kurang lebih 1 bulan di Jalan Pemuda Caringin Kelurahan Margajaya Kecamatan Kota Bogor Barat. Adapun tujuan dari pelaksanaan program ini untuk memberikan informasi yang valid terkait Covid-19 dan cara pencegahannya dimana sasaran utama dalam program ini yaitu Anak-anak. Alasan menjadikan anak sebagai sasaran utama program ini karena anak-anak merupakan salah satu subjek yang rentan terjangkit Covid-19 akibat minimnya informasi yang didapatkan. Dalam mengatasi masalah tersebut kami mengadakan Penyuluhan tentang Covid-19 secara umum, Penyuluhan penggunaan masker dan Penyuluhan asupan gizi seimbang yang dilaksanakan secara daring menggunakan aplikasi whatsapp sebagai media penyebaran informasi. Hasil yang didapatkan dari program tersebut yaitu peningkatan pengetahuan orang tua dan anak terkait Covid-19 dan cara pencegahannya, sehingga orang tua dapat membiasakan anak-anak mereka melakukan pencegahan secara mandiri terhadap Covid-19.
\end{abstract}

Kata Kunci: Jalan Pemuda Caringin, Covid-19, Anak.

\section{PENDAHULUAN}

\section{Latar Belakang}

COVID-19 adalah penyakit menular yang disebabkan oleh jenis coronavirus yang baru ditemukan. Virus tersebut pada mulannya menjangkit warga Wuhan, Tiongkok, bulan desember 2019. Menurut data Kemenkes RI, tercatat pada tanggal 13 September 2020 sebanyak 28.637.952 kasus terkonfirmasi diseluruh dunia, dimana sebanyak 917.417 kasus meninggal dengan angka kematian sebesar 3,2\%. Di Asia Tenggara tercatat sebanyak 5.377.062 kasus terkonfirmasi dengan angka kematian sebanyak 1,7\% (Kemenkes, 2020). Di Indonesia sendiri tercatat sebanyak 214.749 kasus terkonfirmasi dengan angka kematian sebanyak 8.650 jiwa (Kemenkes, 2020). Menurut Pusat Informasi dan Koordinasi COVID-19 Jawa barat, tercatat sebanyak 14.591 kasus terkonfirmasi dengan angka kematian sebanyak 299 jiwa. Sedangkan dibogor sendiri tercatat sebanyak 866 kasus terkonfirmasi dengan angka kematian sebanyak 38 orang.

Jalan Pemuda Caringin RT/RW 03/05 merupakan daearah yang menjadi lokasi pelaksanaan program. Daerah tersebut berada di Kelurahan Margajaya Kecamatan Kota 
Bogor Barat Kota Bogor. Jalan Pemuda Caringin berada di Kecamatan Kota Bogor Barat. Berdasarkan hasil survey tercatat Total Populasi di RT/RW 03/05 yaitu sebanyak 175 warga. Penyebaran kuesioner dilakukan ke 35 sampel warga RT/RW 03/05 Via Daring menggunakan Googleform. Berdasarkan kuesioner yang telah diberikan ke 35 sampel warga, sebanyak 83\% masyarakat sudah menggunakan masker saat berkumpul dengan orang lain dan $71 \%$ masyarakat telah menjaga jarak dengan orang lain.

Berdasarkan capaian tersebut dapat diketahui bahwa masyarakat sudah mengetahui informasi mengenai pencegahan penularan covid-19 namun terdapat 75\% warga masih berjabat tangan dengan orang lain, 54,3\% tidak membersihkan tangan dengan hand sanitizer atau tissu basah setelah memegang sesuatu dimana hal tersebut merupakan kebiasaan buruk yang dapat menularkan Covid-19 yang masih harus diperbaiki lebih baik lagi

\section{Letak Geografis}

Kondisi geografis di Jalan Pemuda Caringan Kelurahan Margajaya memiliki luas wilayah sebesar 116.176 Ha dan Junlah penduduk 5.241 jiwa dengan total 7 RW dan 25 RT. Dari jumlah penduduk 5.241 terdiri dari 1.522 kepala keluarga (2.692 laki-laki dan 2.829 perempuan). dimana mayoritas masyarakatnya mendirikan usaha warung/toko disekitar tempat tinggalnya dan hampir seluruh masyarakat kelurahan Margajaya menganut agama islam. Luas wilayah kelurahan Margajaya tersebut terbagi menjadi 4 wilayah, sebelah merupakan Balungbangjaya, sebelah timur merupakan Bubulak, sebelah selatan merupakan Desa Ciherang dan sebelah barat merupakan desa Dramaga. Status kesehatan masyarakat di Jalan Pemuda Caringin saat ini bisa dikatan sudah lebih baik dimana sekarang sudah dibuat pagar pembatas disisi sungai agar tidak ada lagi yang membuang sampah ke sungai. Lalu disediakan tempat cuci tangan dan tempat khusus untuk penyemprotan disinfektan.

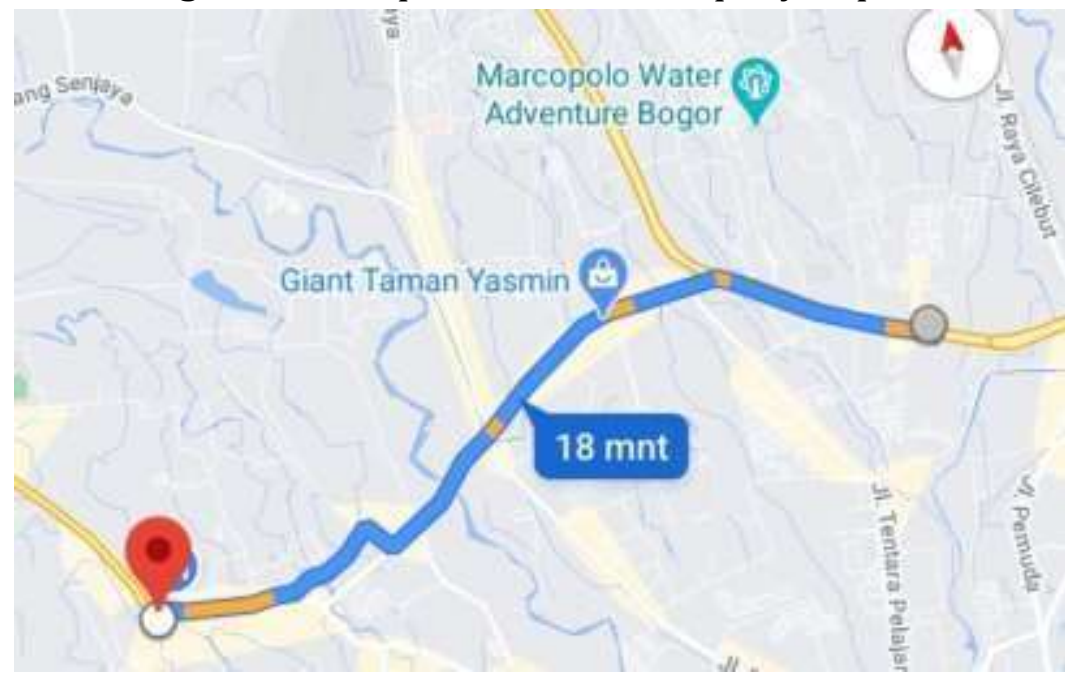

Gambar 1. Lokasi Jalan Pemuda Caringin Kelurahan Margajaya Kecamatan Kota Bogor Barat Kota Bogor 


\section{METODE PELAKSANAAN}

\section{Tahap Pelaksanaan}

Tabel 1. Tahap Pelaksanaan Program

\begin{tabular}{|c|c|c|}
\hline No. & Jenis Kegiatan & Waktu \\
\hline 1. & Penentapan daerah sasaran & 17 Agustus 2020 \\
\hline 2. & Survey daerah sasaran & 20 Agustus 2020 \\
\hline 3. & Perizinan dengan mitra & 20 Agustus 2020 \\
\hline 4. & $\begin{array}{l}\text { Sosialisasi program kepada kader setempat dan mencari dan } \\
\text { meminta nomor whatsapp responden }\end{array}$ & 20 Agustus 2020 \\
\hline 5. & Membuat grup sasaran menggunakan aplikasi whatsapp & 20 Agustus 2020 \\
\hline 6. & Penyusunan materi dan media untuk penyuluhan & 21 Agustus 2020 \\
\hline 7. & $\begin{array}{l}\text { Penyebaran video edukasi tentang Covid-19 via grup } \\
\text { whatsapp }\end{array}$ & 22 Agustus 2020 \\
\hline 8. & $\begin{array}{l}\text { Penyebaran video edukasi tentang cara menggunakan } \\
\text { masker via grup whatsapp }\end{array}$ & 29 Agustus 2020 \\
\hline 9. & $\begin{array}{l}\text { Penyebaran video edukasi tentang asupan gizi seimbang via } \\
\text { grup whatsapp }\end{array}$ & 5 September 2020 \\
\hline 10. & Evaluasi melalui penyebaran asessmen refleksi masyarakat & $\begin{array}{l}\text { 22, } 29 \text { Agustus dan } 5,12 \\
\text { September } 2020\end{array}$ \\
\hline 11. & $\begin{array}{l}\text { Penutupan program dan pemberian tanda terima kasih ke } \\
\text { kader dan responden }\end{array}$ & 16 September 2020 \\
\hline
\end{tabular}

\section{Metode pendekatan}

Dalam hal ini, pendekatan yang kami gunakan adalah:

\section{Partisipasi Masyarakat Dalam Pelaksanaan Program}

Agar dapat berpartisipasi serta menarik antusiasme masyarakat, maka perlu dilakukan beberapa langkah sebagai berikut:

a) Melakukan sosialisasi mengenai program yang akan dilaksanakan ke kader dan masyarakat sasaran.

b) Mengarahkan masyarakat terkait teknis pelaksanaan program.

c) Menjelaskan kepada masyarakat terkait tujuan dan manfaat dari program yang akan dilaksanakan.

Adapun sikap masyarakat terhadap program, yakni sebagai berikut:

a) Masyarakat bersedia menjadi sasaran kegiatan program.

b) Masyarakat mendukung kegiatan yang dirancang oleh mahasiswa.

c) Masyarakat menerima dengan sukarela informasi yang diberikan via daring. 


\section{Langkah evaluasi}

Langkah-langkah evaluasi yang dilakukan dalam program ini yaitu melalui pengisian assesmen refleksi masyarakat yang disebar oleh mahasiswa via daring menggunakan aplikasi whatsapp. Assesmen tersebut berisi beberapa pertanyaan seputar pelaksanaan program. Penyebaran assessmen dilakukan selama 4 minggu pelaksanaan program ke 2 orang sasaran responden yang berbeda setiap minggunya.

\section{REALISASI PROGRAM}

\section{CATER KORONA (Cegah Anak Terjangkit}

\section{a) Penyuluhan Online Tentang Covid- 19 .}

Penyuluhan dilakukan secara daring dengan mengirimkan informasi terkait Covid-19 dalam bentuk video edukasi ke grup whatsapp yang berisikan masyarakat sasaran yaitu para orang tua sebanyak 10 orang.

Tabel 2. Hasil Survey Pengetahuan Covid-19.

\begin{tabular}{|c|c|c|}
\hline Pengetahuan Covid-19 & $\mathrm{n}$ & $\%$ \\
\hline Baik & 28 & $80 \%$ \\
\hline Kurang & 7 & $20 \%$ \\
\hline
\end{tabular}

Berdasarkan tabel survey pengetahuan Covid-19 tercatat sebanyak 28 (80\%) orangtua memiliki tingkat pengetahuan Covid-19 yang baik sedangkan sebanyak 7 (20\%) orangtua memiliki tingkat pengetahuan Covid-19 yang masih kurang. Berdasarkan data tersebut program ini bisa dikatakan berhasil dimana para orangtua telah memiliki tingkat pengetahuan tentang Covid-19 yang baik sehingga para orangtua dapat menerapkan protokol kesehatan yang baik dan benar pada anak-anak mereka agar terhindar dari Covid-19.

Hal yang diperoleh yaitu:

$\checkmark$ Masyarakat mengatahui informasi terkini terkait Covid-19.

$\checkmark$ Masyarakat mengetahui tentang cara pencegahan Covid-19.

\section{b) Penyuluhan Online Tentang Penggunaan Masker.}

Penyuluhan dilakukan secara daring dengan mengirimkan informasi terkait penggunaan masker dalam bentuk video edukasi ke grup whatsapp yang berisikan masyarakat sasaran yaitu para orang tua sebanyak 10 orang.

Tabel 3. Hasil Survey Penggunaan Masker.

\begin{tabular}{|c|c|c|}
\hline Penggunaan Masker & $\mathrm{n}$ & $\%$ \\
\hline Sudah & 29 & $83 \%$ \\
\hline Belum & 6 & $17 \%$ \\
\hline
\end{tabular}

Berdasarkan tabel penggunaan masker, tercatat sebanyak 29 (83\%) orangtua sudah memberitahu anak-anak mereka tentang penggunaan masker yang baik dan benar, sedangkan sebanyak 6 (17\%) orangtua belum memberitahu anak- anak mereka tentang penggunaan 
masker yang baik dan benar. Berdasarkan data tersebut program ini dapat dikatakan berhasil dikarenakan para orangtua sudah memberitahu dan membiasakan anak-anak mereka tentang penggunaan masker yang baik dan benar.

Hal yang diperoleh yaitu:

$\checkmark$ Orang tua mengetahui tentang cara penggunaan masker yang baik dan benar.

$\checkmark$ Orang tua membiasakan anak mereka memakai masker saat berpergian.

\section{c) Penyuluhan Online Tentang Asupan Gizi Seimbang.}

Penyuluhan dilakukan secara daring dengan mengirimkan informasi terkait asupan gizi seimbang dalam bentuk video edukasi ke grup whatsapp yang berisikan masyarakat sasaran yaitu para orang tua sebanyak 10 orang.

Tabel 4. Hasil Survey Pemberian Asupan Gizi Seimbang

\begin{tabular}{|c|c|c|}
\hline $\begin{array}{l}\text { Pemberian Asupan Gizi } \\
\text { Seimbang }\end{array}$ & $\mathrm{n}$ & $\%$ \\
\hline Sudah & 18 & $54 \%$ \\
\hline Belum & 17 & $46 \%$ \\
\hline
\end{tabular}

Berdasarkan tabel pemberian asupan gizi seimbang, tercatat sebanyak 18 (54\%) orangtua sudah memberikan anak-anak mereka asupan gizi yang seimbang, sedangkan 17 (46\%) orangtua belum memberikan anak-anak mereka asupan gizi yang seimbang.

Hal yang diperoleh yaitu:

$\checkmark$ Orang tua mengetahui tentang apa saja asupan gizi yang seimbang untuk anak-anak mereka.

$\checkmark$ Orang tua memberi anak-anak mereka makanan yang mengandung zat gizi yang seimbang.

$\checkmark$ Orang tua mengetahui manfaat pemberian makanan bergizi seimbang untuk anak.

\section{PENUTUP}

\section{Kesimpulan}

Program pengabdian masyarakat ini berlangsung selama kurang lebih 1 bulan. Jalan Pemuda Caringin merupakan daerah yang bisa dikatakan sudah memadai dalam ketersedian fasilitas kesehatan di daerah tersebut. Namun perilaku masyarakat dalam upaya pencegahan Covid-19 masih dapat ditingkatkan lagi. Anak-anak merupakan golongan yang rentan terhadap infeksi Covid-19 dikarenakan masih minimnya informasi yang didapatkan oleh mereka. Peran orang tua sangat penting dalam upaya pencegahan Covid-19 pada anak dikarenakan orang tua merupakan sumber terpercaya yang dimiliki anak dalam mendapatkan informasi. Oleh karena itu dalam program ini kami mengadakan program yang bertujuan untuk meningkatkan pengetahuan orang tua terhadap anak-anak mereka terkait Covid-19 dan cara pencegahannnya serta merubah kebiasaan anak-anak agar dapat melakukan upaya pencegahan Covid-19 secara mandiri. Program yang dilaksanakan antara lain penyuluhan online tentang Covid-19 secara umum, penyuluhan online tentang penggunaan masker dan penyuluhan online tentang asupan gizi yang seimbang. Berdasarkan uraian program yang 
dipaparkan pada bab sebelumnya selama pelaksanaan program di Jalan Pemuda Caringin Kelurahan Margaja Kecamatan Kota Bogor Barat, berikut kami paparkan kesimpulan yang kami peroleh:

1. Terealisasinya program-program pengabdian masyarakat di Jalan Pemuda Caringin Kelurahan Margaja Kecamatan Kota Bogor Barat.

2. Terjalinnya kerjasama antara mahasiswa, mitra dan masyarakat setempat terkait pelaksanaan program.

3. Terbentuknya perubahan perilaku kebiasaan baru bagi para orang tua dan anak-anak mereka dalam menyingkapi pandemi Covid-19.

4. Meningkatnya pengetahuan orang tua dan anak terkait Covid-19.

\section{Saran}

Berdasarkan program pengabdian masyarakat yang telah dilaksanakan oleh mahasiswa kelompok 2 Universitas Ibn Khaldun Bogor yang dilaksanakan di Jalan Pemuda Caringin Kelurahan Margaja Kecamatan Kota Bogor Barat, kami memberikan beberapa hal sebagai saran untuk perkembangan program kerja kami selanjutnya:

1. Perlu adanya kerjasama dan dukungan yang baik dari mitra setempat dengan masyarakat dalam mensukseskan program.

2. Partisipasi masyarakat setempat untuk ikut serta menjaga dan melanjutkan programprogram yang telah dijalankan mahasiswa.

3. Harus mampu merealisasikan program- program yang telah dirancang terutama penyuluhan yang dilakukan secara online.

4. Mahasiswa harus menekankan setiap dosen pembimbing agar selalu memantau kegiatan yang dilakukan mahasiswa agar program kerja dapat terlaksana secara efektif dan efisien.

\section{DAFTAR PUSTAKA}

Asnifatima A. Pola Kecenderungan Spasial Kejadian Malaria (Studi Kasus; di Kabupaten Kepulauan Selayar Tahun 2011 - 2013). Hearty Jurnal Kesehatan Masyarakat. 2017;5(1):1-12. http://ejournal.uikabogor.ac.id/index.php/Hearty/article/view/1051/865.

Asnifatima, A., Prakoso, I., and Fatimah, A. (2017). Faktor Risiko Keluhan Computer Vision Syndrome (CVS) Pada Operator Warung Internet Di Kecamatan Bojong Gede, Kabupaten Bogor Tahun 2017. Hearty Jurnal Kesehatan Masyarakat, 5(2), pp.1-7.

Asnifatima, A., Irfan, A. M., \& Putri, K. A. (2018). Pemberdayaan Masyarakat Melalui Pengelolaan Sampah Rumah Tangga Di Desa Cimanggu Satu. Abdi Dosen : Jurnal Pengabdian Pada Masyarakat, 2(3). https://doi.org/10.32832/abdidos.v2i3.181

Asnifatima A, Parinduri SK, Aligori A. (2020). Risiko dan Karakterisitik Penderita Toksoplasmosis berdasarkan Demografi, Keberadaan Hewan Peliharaan, Hygiene dan Sanitasi. Heart, Jurnal Kesehatan Masyarakat,8(X), 41-49.

A Asnifatima, R Listyandini. (2020). HUBUNGAN PENGGUNAAN LEM DENGAN KONDISI FISIOLOGI PEKERJA HOME INDUSTRY DI RW04 KELURAHAN PAMOYANAN KOTA BOGOR TAHUN 2019. PROMOTOR 3 (1), 7-17

A Asnifatima. (2020). Hubungan Infertilitas dengan Toksoplasmosis pada Wanita Sudah 
Menikah. PROSIDING LPPM UIKA BOGOR

A Asnifatima, AD Martin, S Kalbu. (2020). PENGOLAHAN SAMPAH MANDIRI DENGAN INSENERASI SEDERHANA MINIM ASAP (INSEMA) DI KELURAHAN BOJONGKERTA, KEC. BOGOR SELATAN, KOTA BOGOR TAHUN 2019. Abdi Dosen: Jurnal Pengabdian Pada Masyarakat 4 (1), 1-12

D Melinda, A Fathimah, A Asnifatima. (2021). ANALISIS RISISKO KESELAMATAN DAN KESEHATAN KERJA DI AREA UTILITY PT KALBE MILKO INDONESIA KECAMATAN CARINGIN KABUPATEN BOGOR TAHUN 2018. PROMOTOR 3 (6), 569-576

FD Firdayanti, A Asnifatima. (2021). PEMBERDAYAAN MASYARAKAT DALAM MEWUJUDKAN PROGRAM AGENT PERUBAHAN PEDULI COVID-19 (AADC-19) DI KAMPUNG NYENCLE. PROMOTOR 4 (5), 499-510

FW Ardianty, A Fathimah, A Asnifatima. (2021). HUBUNGAN ANTARA PAJANAN KEBISINGAN DENGAN GANGGUAN NON-AUDIOTORY PADA PETUGAS KEAMANAN DALAM (PKD) PT KERETA API INDONESIA (KAI) DI STASIUN BOGOR TAHUN 2020. PROMOTOR 4 (2), 114-121

Hartanti, HF, Asnifatima, A \& Fatimah, A. Faktor Risiko yang Berhubungan Dengan Keluhan Carpal Tunnel Syndrome Pada Pekerja Operator Komputer Bagian Redaksi di Harian Metropolitan Bogor Tahun 2018, Jurnal Mahasiswa Kesehatan Masyarakat. 2018

Kemenkes. 2020. Infeksi Emerging. Dapat diakses di https://infeksiemerging.kemkes.go.id/?s=Jawa+barat\#.Xz1Gsh 4xd-F

Meilani, F., Asnifatima, A., \& Fathimah, A. (2018). Faktor-faktor Risiko Yang Mempengaruhi Keluhan MUSCULOSKELETAL DISORDER (MSDs) Pada pekerja Operator Sewing DI PT DASAN PAN FASIFIC INDONESIA Tahun 2018. Promotor Jurnal Mahasiswa Kesehatan Masyarakat, 1(1), 1-6.

NF Ainiyyah, A Fathimah, A Asnifatima. (2021). HUBUNGAN ANTARA KEBISINGAN TERHADAP STRES KERJA PADA PEKERJA DI BAGIAN MIXING PT. ELANGPERDANA TYRE INDUSTRY TAHUN 2020. PROMOTOR 4 (4), 338-348

NR Rizqi, A Asnifatima, R Listyandini. (2021). GAMBARAN PAPARAN RISIKO CACINGAN PADA PETUGAS PENGANGKUT SAMPAH DI KECAMATAN BOJONGGEDE KABUPATEN BOGOR TAHUN 2020. PROMOTOR 4 (4), 349-358

NE Yuliana, A Asnifatima, A Fathimah. (2021). FAKTOR-FAKTOR YANG BERHUBUNGAN DENGAN KELUHAN SUBJEKTIF DERMATITIS KONTAK PADA PEKERJA PABRIK TAHU DI KECAMATAN CITEUREUP KABUPATEN BOGOR TAHUN 2020. PROMOTOR 4 (3), 253 261

Piskobar. 2020. Statistik kasus Covid-19 Provinsi Jawa Barat. Dapat diakses di https://pikobar.jabarprov.go.id/ data

Pusat Informasi dan Koordinasi Kota Bogor. 2020. Statistik kasus Covid-19 Kota Bogor. Dapat diakses di http://www.covid19.kotabogor.go. id/

Profil Wilayah Kota bogor. 2020. Data Demografi Kelurahan Margajaya. Dapat diakses di https://kotabogor.go.id/index.php/pr ofilwilayah/detail/38/kelurahan

Pratama S., Asnifatima A., Ginanjar R., 2019 , Faktor-Faktor Yang Berhubungan Terhadap Postur Kerja Dengan Keluhan Nyeri Punggung Bawah Pada Pengemudi Bus Pusaka Di Terminal Baranangsiang Kota Bogor Tahun 2018, Promotor Jurnal Mahasiswa 
Kesehatan Masyarakat Vol.2, No.4

Raya, M. R., Asnifatimah, A. and Ginanjar,R. 2018.Faktor-Faktor yang Mempengaruhi Keluhan GangguanPendengaran Pada Supir Bus POPusaka Di Terminal Baranangsiang Kota Bogor Tahun 2018.Jurnal Promotor Vol 2 No 2.

R Ginanjar, A Asnifatima. (2021). ANALISIS KEBUTUHAN SISTEM TANGGAP DARUTAT DI SEKOLAH AT TAUFIQ KOTA BOGOR TAHUN 2019. PROMOTOR 3 (6), 614-623

SK Parinduri, A Asnifatima, MAA Saci, A Nasution. (2021). Peluang dan Tantangan Promosi

Kesehatan Kader Kesehatan Remaja Kota Bogor. Jurnal Ilmu Kesehatan Masyarakat 10 (01), 46-54

SK Parinduri, A Asnifatima, D Ferdian. (2020). Analysis of Health Promotion Methods for

Adolescent Health Cadres in Bogor City: A Case Study. Jurnal Ners dan Kebidanan Indonesia 8 (4), 16-17

WHO. 2020. Pertanyaan dan jawaban terkait Coronavirus. Dapat diakses di https://www.who.int/indonesia/news/novel-coronavirus/qa-for-public

WHO. 2020. Tatalaksana klinis infeksi saluran pernafasan akut berat (SARI) Suspek Covid-19. 